\title{
Biomarkers of Oxidative Stress in Major Depressive Disorder
}

\author{
Rania Ahmed Hamed ${ }^{1 \star}$, Heba A. Elmalt ${ }^{2}$, Abeer A. A. Salama ${ }^{3}$, Sarah Y. Abozaid ${ }^{4}$, Amani S. Ahmed $^{5}$ \\ ${ }^{1}$ Department of Psychiatry, Faculty of Medicine for Girls, Al-Azhar University, Cairo, Egypt; ${ }^{2}$ Department of Medical Biochemistry, \\ National Research Centre, Cairo, Egypt; ${ }^{3}$ Department of Pharmacology, National Research Centre, Cairo, Egypt; ${ }^{4}$ Department \\ of Clinical Pathology, Faculty of Medicine for Girls, Al-Azhar University, Cairo, Egypt; ${ }^{5}$ Department of Community, Environmental \\ and Occupational Medicine, Faculty of Medicine, Zagazig University, Zagazig, Egypt
}

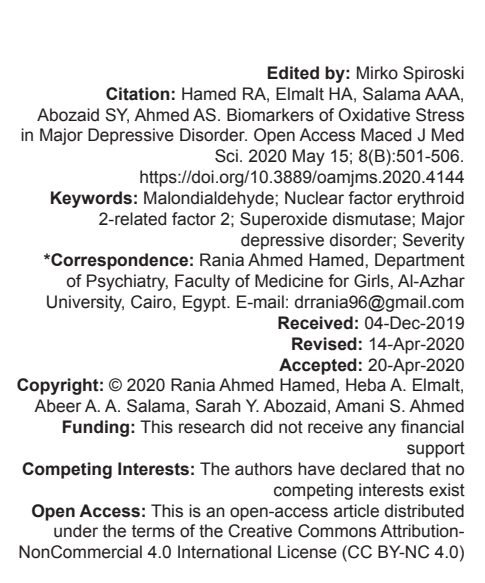

Abstract

BACKGROUND: Many data support that oxidative stress and inflammation represent a pathway to pathology in a number of depressed patients. Therefore, investigating this pathway presents an area for developing potential therapeutic strategies for depression.

AIM: This study compares the serum level of malondialdehyde (MDA), superoxide dismutase (SOD), and nuclear factor erythroid 2-related factor 2 (Nrf2) in depressed and non-depressed subjects and correlate between their levels with severity of disorder, socio-demographic characteristics, previous hospitalization, and number of episodes.

METHODS: A total of 60 patients diagnosed with major depressive disorder (MDD) from the Psychiatric Outpatien Clinic in Al-Zahra University Hospital, Cairo, Egypt, during the period from July 1, 2018, to December 31, 2018. A cross-matched control group of 60 subjects was selected from employers working in the hospital, complete psychiatric history, Hamilton Depression rating scale was done and serum levels of MDA, Nrf2, and SOD were estimated.

RESULTS: No statistical difference between patient and control group was observed regarding age, sex, education, and marital status. The number of patients with mild depression was $28(46.7 \%)$, moderate depression $18(30 \%)$, and severe depression 14 (23.3\%). The mean duration of illness in years was 6.13 , and mean number of episodes was 3.66. MDA level was significantly elevated in the patient group than the control one. Meanwhile, SOD and Nrf2 were significantly lower in the patient group than the control. There was significant relationship between duration of illness and number of episodes and MDA, Nrf2, and SOD levels.

CONCLUSION: Our results indicate that oxidative stress can attribute to the occurrence of MDD.

\section{Introduction}

Depression is a state of low mood and demotivation affecting individual's feelings, cognition, and behaviors. It is the most common psychiatric disorder and is considered a high-risk factor of suicide [1].

Researchers suggest that depression does not stem from simply too much or too little brain chemicals. Many data support the hypothesis that inflammation represents a pathway to pathology in a number of depressed patients. Therefore, investigating this pathway presents an area for developing potential therapeutic strategies for depression [2].

According to the $\mathrm{WHO}$; more than 300 million people suffer from depression. The WHO identified strong relations between depression and other disorders. It increases the risk of substance use disorders, diabetes mellitus, and heart disease [3]. At worst, it leads to suicide which claims 800,000 of lives every year [4]. Depression induces global disability (7.5 of all years lived with disability in 2015). Major depression is projected to become the second leading cause of disability all over the world [3].
A growing body of evidence supports the relation between depression and inflammation [5]. Studies showed more cytokines production in medicated depressed or drug free patients than controls [6]. Oxidative stress plays a role in neuronal cell death directly or through an inflammatory process. There is an increasing evidence of excess level of reactive oxygen species (ROS) and inflammatory biomarkers in depressed patients with activation of stress kinases promoting further oxidative stress and neuroinflammation with subsequent cell death. Oxidative stress leads to oxidized lipids, proteins, and nucleic acids as result of greater ROS [7] targeting fatty acids, monoamines of the brain. Monoamine oxidation produces superoxide anions; therefore, a critical balance is required between free radicals and antioxidants mechanisms.

Oxidative stress damage is evidenced by an increased level of malondialdehyde (MDA), polyunsaturated fatty acid peroxidation by product [8]. In the same context, nuclear factor erythroid 2-related factor 2 (Nrf2) is the master regulator of inducible antioxidant responses [9]. The activation of Nrf2 plays a key role in inflammation [10] through the reduction of ROS production 
and the macrophage M1 phenotype [11], regulating antioxidant response element (ARE) gene expression The Keap1 (Kelch-like ECH-associated protein 1), and the recruitment of inflammatory cells. During oxidative stress, free Nrf2 translocates to the nucleus and binds to ARE genes such as hemeoxygenase-1 inhibiting the NF-KB pathway which leads to downregulation of pro-inflammatory cytokines [12]. In inflammatory disorders and neurodegenerative diseases, Nrf2 stimulator has become an important therapeutic strategy [13], [14], [15]. Hence, the discovery of new Nrf2 stimulator for clinical study is an essential target in drug discovery.

Nrf2 has a crucial role in inflammation which is implicated in depression. Its deletion in mice results in reduced dopamine and serotonin in prefrontal cortex [16]. Furthermore, in a chronic stress paradigm, Nrf2 has a mechanism responsible for antidepressant response [17]. A study by Martín-Hernández (2018) [18] was done on postmortem brains of depressed patients showed decreased expression of Nrf2 in the dorsolateral prefrontal cortex. Furthermore, superoxide dismutase (SOD) is an enzyme that converts superoxide anion radicals to molecular oxygen and hydrogen peroxide controlling ROS [19].

\section{Aim}

The aim of the study was to compare the serum levels of MDA, Nrf2, and SOD in depressed and non-depressed subjects and to correlate between their levels with the severity of disorder, socio-demographic characteristics, previous hospitalization, and number of episodes.

\section{Participants}

A convenience sample of 60 patients diagnosed with major depressive disorder (MDD) from the Psychiatric Outpatient Clinic in Al-Zahra Hospital, Cairo, Egypt. The diagnosis was based on the DSM 5 criteria for MDD. A cross-matched control group comprised 60 subjects were selected from employers working in the hospital. All subjects provided written informed consent, approved applying personal data for research. The study was done consistent with good clinical practice and Declaration of Helsinki and the World Health Organization guidelines.

\section{Inclusion criteria}

The following criteria were included in the study:

1. Age range between 18 and 55 .

2. Both sexes were included.

\section{Exclusion criteria}

The following criteria were excluded from the study:
1. Comorbid psychiatric disorders.

2. Medical illnesses such as endocrine, metabolic, neurological, or autoimmune disorders.

3. Infections, inflammatory reactions, or allergy within the past 2 weeks preceding blood sampling or antioxidant medication.

\section{Measures}

All subjects were subjected to the following:

1. Complete psychiatric sheet and examination and diagnosis were based on DSM 5 criteria for diagnosis of MDD.

2. Hamilton depression rating scale (HAMD) [20], its Arabic version [21]: A useful scale used to determine patients' severity of depression.

3. Serum levels of MDA and SOD were estimated using Biodiagnostic kit, Egypt.

4. Serum Nrf2 levels was determined using Elabscience Biotechnology Co. Ltd. Enzymelinked immunosorbent assay (ELISA) kit.

\section{Procedure}

Blood samples were taken from both groups under sterile conditions. Serum levels of MDA and SOD were estimated according to the methods described by Misra and Fridovich [22] and Ohkawa et al. [23], respectively.

Serum Nrf2 levels was determined using Elabscience Biotechnology Co. Ltd. ELISA kit. We followed the manufacturer's instructions for definition and calculating results. Standards and samples were pipetted into wells with immobilized antibodies specific for human Nrf2, and then were incubated. After incubation and washing, biotinylated antihuman Nrf2 antibody was added. Having washed away any unbound substances, biotinylated antibody and horseradish peroxidase-conjugated streptavidin were pipetted into the wells, which were washed once again. tetramethylbenzidine substrate solution was added to the wells; color developed proportionally to the amount of Nrf2 bound. Color development was discontinued (Stop Solution) and its intensity was measured using the Thermo Labsystems Multiskan Ascent 354 (Lab Recyclers) at $450 \mathrm{~nm}$.

\section{Statistical analysis}

The Statistical Package for the Social Sciences (SPSS version 21.0) was used for data entry and analysis. Descriptive statistics were computed in the form of frequency and percentage for categorical data and in the form of measures of central tendency (arithmetic mean) and measures of dispersion (standard deviation) for continuous variables. Chi-square test was used to test for the association and/or difference 
between categorical variables. Student's t-test was used for comparing two means and ANOVA for comparing more than 2 means. Multiple comparisons among sample means were checked by post hoc LSD. Pearson's correlation coefficient ( $r$ ) or spearmen's rank order correlation coefficient was used for testing the association between two variables. Differences were considered as statistically significant when $p=0.05$.

\section{Results}

The socio-demographic data showed that cases were matching with the controls, no statistical difference between patient and control groups was observed regarding age, sex, education, and marital status (Table 1).

Table 1: Socio-demographic characteristics of both patients and control groups

\begin{tabular}{lllll}
\hline Characteristics & $\begin{array}{l}\text { Patient } \\
\text { group } \mathrm{n}=60\end{array}$ & $\begin{array}{l}\text { Control } \\
\text { group } \mathrm{n}=60\end{array}$ & Sig test & $\mathrm{p}$ value \\
\hline Age (years) (mean $\pm \mathrm{SD})$ & $41.03 \pm 4.46$ & $42.8 \pm 4.28$ & $\mathrm{t}$-test $=2.2 \mathrm{df}=118$ & $>0.05$ \\
Gender & 18 & 22 & $\chi^{2}=0.6$ & $>0.05$ \\
$\quad$ Males & 42 & 38 & $\mathrm{df}=1$ & \\
$\quad \begin{array}{l}\text { Females } \\
\text { Education }\end{array}$ & & & & $>0.05$ \\
$\quad$ Primary & 34 & 30 & $\chi^{2}=2$ & \\
$\quad$ Secondary & 18 & 16 & $\mathrm{df}=4$ & \\
$\quad$ High & 8 & 14 & & \\
Marital status & & & $\chi^{2}=6.23$ & \\
$\quad$ Single & 4 & 10 & $\mathrm{df}=6$ & \\
$\quad$ Married & 36 & 28 & & \\
$\quad$ Divorced & 14 & 10 & & \\
$\quad$ Widowed & 6 & 12 & &
\end{tabular}

According to HAMD, the number of patients with mild depression was $28(46.7 \%)$, moderate depression was 18 (30\%), and severe depression was 14 (23.3\%). The mean duration of illness in years was 6.13 and the mean number of episodes was 3.66 (Table 2).

Table 2: Severity of depression according to Hamilton depression rating scale and disease characteristics

\begin{tabular}{ll}
\hline Disease characteristics & Patient group $\mathrm{n}=60$ \\
\hline HDRS & $\mathrm{n}(\%)$ \\
Mild depression $\mathrm{n}(\%)$ & $28(46.7)$ \\
Moderate depression $\mathrm{n}(\%)$ & $18(30)$ \\
Severe depression $\mathrm{n}(\%)$ & $14(23.3)$ \\
Duration of illness in years (Mean $\pm \mathrm{SD})$ & $6.13 \pm 2.4$ \\
Number of episodes(Mean \pm SD) & $3.66 \pm 1.43$ \\
\hline HDRS: Hamilton depression rating scale, SD: Standard deviation. &
\end{tabular}

Comparison between patient and control groups regarding MDA, SOD, and Nrf2 showed that the MDA level was higher in the patient group than the control one with statistical significance; meanwhile, SOD and Nrf2 were significantly lower in the patient group than the control one $(20.46 \pm 2.55 \mathrm{pg} / \mathrm{ml}, 42.2 \pm$ $23.8 \mu / \mathrm{ml}, 0.4 \pm 0.1 \mathrm{pg} / \mathrm{ml}$ vs. $12.74 \pm 0.26 \mathrm{pg} / \mathrm{ml}$, and

Table 3: Comparison between patient and control groups regarding MDA, SOD, and Nrf2

\begin{tabular}{lllll}
\hline Biomarkers & Control group $n=60$ & Patient group $n=60$ & t-test & $p$ value \\
\hline MDA & $12.74 \pm 0.26$ & $20.46 \pm 2.55$ & 23.27 & 0.001 \\
SOD & $131.02 \pm 17.45$ & $42.2 \pm 23.8$ & 23.29 & 0.001 \\
Nrf2 & $1.02 \pm 0.04$ & $0.4 \pm 0.1$ & 42.93 & 0.001 \\
\hline MDA: Malondialdehyde, SOD: Superoxide dismutase, Nrf2: Nuclear factor erythroid 2-related factor 2.
\end{tabular}

$131.02 \pm 17.45 \mu / \mathrm{ml}, 1.02 \pm 0.04 \mathrm{pg} / \mathrm{ml}$, respectively) (Table 3).

Comparison between mild, moderate, severe depression, and control groups regarding MDA, SOD, and Nrf2 showed that patients with severe depression had significantly higher levels of MDA than those with mild depression; they also have significantly lower levels of SOD and Nrf2 than those with moderate depression and mild depression, respectively (Table 4).

Table 4: Comparison between mild, moderate, severe depression, and control groups regarding MDA, SOD, and Nrf2

\begin{tabular}{llllll}
\hline Biomarkers & Control group & $\begin{array}{l}\text { Mild } \\
\text { depression }\end{array}$ & $\begin{array}{l}\text { Moderate } \\
\text { depression }\end{array}$ & $\begin{array}{l}\text { Severe } \\
\text { depression }\end{array}$ & p value \\
\hline Malondialdehyde & $12.74 \pm 0.26$ & $18.8 \pm 2.95^{\mathrm{a}}$ & $21.79 \pm 0.43^{\mathrm{a}}$ & $22.08 \pm$ & $<0.001$ \\
& & & & $0.18^{\mathrm{a}, \mathrm{b}}$ & \\
& & & &
\end{tabular}

Superoxide $\quad 131.02 \pm 17.45 \quad 56.03 \pm 14.68^{\mathrm{a}} \quad 46.99 \pm 18.54^{\mathrm{a}} \quad 8.4 \pm 1.7^{\mathrm{a}, \mathrm{b}, \mathrm{c}} \quad<0.001$ dismutase

Nrf2

$1.02 \pm 0.04 \quad 0.48 \pm 0.091^{\mathrm{a}} \quad 0.35 \pm 0.06^{\mathrm{a}} \quad 0.32 \pm 0.05^{\mathrm{a}, \mathrm{b}, \mathrm{c}}<0.001$

${ }^{a}$ Significantly different from control, ${ }^{\mathrm{b} S}$ Significantly different from mild, ${ }^{\circ} \mathrm{S}$ ignificantly different from moderate, post hoc LSD at $p=0.05$. MDA: Malondialdehyde, SOD: Superoxide dismutase, Nrf2: Nuclear factor erythroid 2-related factor 2 .

Relationship between MDA, SOD, Nrf2, and other variables revealed that there was strong positive correlation between MDA, SOD, Nrf2 levels, and duration of illness in years and number of episodes and no correlation was found between MDA, SOD, Nrf2, and age and gender (Table 5).

Table 5: Relationship between MDA, SOD, Nrf2, and some variables (Age, gender, duration of illness, and number of episodes) in patient group

\begin{tabular}{lll}
\hline Variables & Patients & p value \\
\cline { 2 - 3 } & $\mathrm{R}$ & $>0.05$ \\
Age and MDA & 0.05 & $>0.05$ \\
Gender and MDA & 0.21 & $<0.001$ \\
Duration of illness and MDA & 0.76 & $<0.001$ \\
Number of episodes and MDA & 0.81 & $>0.05$ \\
Age and SOD & 0.23 & $>0.05$ \\
Gender and SOD & 0.06 & $<0.001$ \\
Duration of illness and SOD & 0.72 & $<0.001$ \\
Number of episodes and SOD & 0.73 & $>0.05$ \\
Age and Nrf2 & 0.23 & $>0.05$ \\
Gender and Nrf2 & 0.11 & $<0.001$ \\
Duration of illness and Nrf2 & 0.78 & $<0.001$ \\
Number of episodes and Nrf2 & 0.84 &
\end{tabular}

MDA: Malondialdehyde, SOD: Superoxide dismutase, Nrf2: Nuclear factor erythroid 2-related factor 2 .

\section{Discussion}

Recent researches showed that major depression is associated with activation in immune-inflammatory markers and there is an evidence that this activation is related to overproduction of ROS [24]. Some studies reported an increase in catabolism (oxidation) of monoamine neurotransmitters in MDD. It was also hypothesized that alterations in some lipids lead to changes in serotonin and noradrenaline which is thought to be related to depression [25]. Moreover, an established relationship between lipid peroxidation and ROS is found [26].

In our study, we examined the levels of MDA, SOD, and Nrf2 in the sera of 60 depressed patients and 60 controls and we found that MDA was significantly higher in patients than the control $(20.46 \pm 2.55 \mathrm{pg} / \mathrm{ml}$ 
vs. $12.74 \pm 0.26 \mathrm{pg} / \mathrm{ml}$ ) and these results are consistent with those of Billici et al. [27] who included 30 depressed patients and 30 control and found that plasma MDA was significantly higher in depressed patients than control $(4.82 \pm 1.3 \mu \mathrm{mol} / \mathrm{l}$ vs. $2.89 \pm 1.1)$. Moreover, they found a positive correlation with its plasma level and both the number of episodes and duration of illness $(r=0.28$, $p<0.05)$.

Likewise, Bajpai et al. [28] examined the MDA level in 60 depressed patients and 40 controls and found that its level was significantly higher in patients than controls $(1.95 \pm 1.04 \mathrm{mmol} / \mathrm{L}$ vs. $0.366 \pm 0.175)$.

Similarly, Camkurt et al. [29] found that MDA level was significantly higher in patients with major depression than controls with medians at 4.04 $\mathrm{nmol} / \mathrm{mg}$ and $1.64 \mathrm{nmol} / \mathrm{mg}$, respectively. They also examined SOD which was significantly decreased in depressed patients than controls with means at $143 \mu / \mathrm{mg}$ and 298.12/mg, respectively, $p<0.001$ and this matches with our study in which the SOD level was significantly less in patient group than the control one (42.2 \pm 23.8 vs. $131.02 \pm 17.45)$. Bajpai et al. [28] found that MDA was higher in patients than the controls $(1.95 \pm 1.04 \mathrm{mmol} / \mathrm{l}$ vs. $0.366 \pm 0.175)$ and SOD was lower in patients $(0.123 \pm 0.068 \mu \mathrm{g} / \mathrm{ml}$ vs. $0.177 \pm 0.042$ )

Likewise, several studies suggested elevated MDA levels in depression and a reduction following antidepressant therapy was documented by Mazereeuw et al. [30].

The present results suggest that oxidative stress, which is evidenced by elevated MDA marker levels, is disturbed in depressed patients.

Regarding Nrf2, in our study, we found that Nrf2 was significantly decreased in depressed patients than controls. A recent study showed the reduced $(-21 \%)$ expression of Nrf2 in the dorsolateral prefrontal cortex from MDD patients [18].

These results suggest that decreased Keap1Nrf2 signaling plays a key role in the pathophysiology of mood disorders such as MDD and bipolar disorder [31].

Only few studies have evaluated oxidative stress and the severity of depression.

In our study, patients with severe depression had significantly higher levels of MDA than those with mild depression. This was consistent with the study of Rangaswamy and Swath [32] who found that there was moderate positive correlation between MDA levels and clinical severity of depression as measured by 21 -item Hamilton rating scale for depression score which was found to be statistically significant $(r=0.317, p=0.025)$, and the study of Kotan et al. [33] who found that there was a positive correlation between the severity of depressive symptoms and SOD activity. This was in contrary to Bal et al. (2012) [34] who studied 42 patients (37 women, and 5 men) diagnosed with MDD and no correlation was found between HAMD scores and MDA at patient group. Furthermore, our study revealed significantly lower levels of SOD and Nrf2 in patients with moderate depression and mild depression, respectively, compared to control group. This was consistent with the study of Rawdin et al. [35] who found that Nrf 2 did differ along the continuum of depressive symptom severity across groups. Furthermore, Sarandol et al. [36] found a positive correlation between the severity of depressive symptoms and SOD activity exists.

Researchers have proposed that oxidative stress is one of the potential pathogenic mediators for depression because it easily affects neuronal cell functions of the brain and hence the relation is settled between oxidative stress and depressive symptom scores.

In the current study, there was a significant relationship between the duration of illness and number of episodes and both high levels of MDA and low levels of SOD and Nrf2 with strong positive correlation. This was consistent with the previous studies such as Billici et al. [27], Stefanescu and Ciobica (2012) [37].

This can be attributed to explanations proven by recent research which stated that inflammation and mitochondrial oxidative process which occur in depression generate free radicals excessively with subsequent increase in MDA, these species react with macromolecules of the cell such as polyunsaturated fatty acids, DNA, proteins, and hence, damaging them [28], [38]. Therefore, definitely, the more the duration of illness, the more the number of episodes, the more free radicals and tissue destruction with higher levels of MDA.

Hence, to enhance personalized treatment for depressed patients, accurate prediction and detection of factors contributing to severity and recurrence of episodes is mandatory.

\section{Conclusion}

Our results indicate that oxidative stress can affect MDD, as free radicals are generated together with antioxidant deficiency; this can attribute to the occurrence of MDD and gives us a better understanding of the pathophysiology of depression and hence developing new therapeutic strategies.

\section{Acknowledgment}

The authors would like to express their gratitude to all patients for their participation in this study. 


\section{References}

1. Mogi T, Toda H, Yoshino A. Clinical characteristics of patients with diagnostic uncertainty of major depressive disorder. Asian J Psychiatry 2017;30:159-62. https://doi.org/10.1016/j. ajp.2017.10.001

PMid:29055250

2. Stapelberg NJ, Pratt R, Neumann DL, Shum DH, Brandis S, Muthukkumarasamy $\mathrm{V}$, et al. From feedback loop transitions to biomarkers in the psycho-immune-neuroendocrine network: Detecting the critical transition from health to major depression. Neurosci Biobehav Rev 2018;90:1-5. https://doi.org/10.1016/j. neubiorev.2018.03.005

3. World Health Organization. "Depression: Let's Talk" Says WHO, as Depression Tops List of Causes of III Health. Geneva: World Health Organization; 2017. https://www.who.int/news$\mathrm{room} /$ detail/30-03-2017--depression-let-s-talk-says-who-asdepression-tops-list-of-causes-of-ill-health. [Last accessed on 2017 Mar 30]. https://doi.org/10.7748/mhp.11.2.4.s2

4. World Health Organization. Preventing Suicide: A Global Imperative. Geneva: World Health Organization; 2014. Available from: https://www.who.int/mental_health/suicideprevention/world_report_2014/en. https://doi.org/10.1037/ e400972004-001

5. Miller A. Five Things to know about Inflammation and Depression. Vol. 35. Psychiatric Times; 2018.

6. Kohler CA, Freitas TH, Stubbs B, Maes M, Solmi M, Veronese $\mathrm{N}$, et al. Peripheral alterations in cytokine and chemokine levels after antidepressant drug treatment for major depressive disorder: Systematic review and meta-analysis. Mol Neurobiol. 2018;55(5):4195-206. https://doi.org/10.1007/ s12035-017-0632-1

PMid:28612257

7. Semba RD, Ferrucci L, Sun K, Walston J, Varadhan R, Guralnik JM, et al. Oxidative stress is associated with greater mortality in older women living in the community. J Am Geriatr Soc 2007;55(9):1421-5. https://doi. org/10.1111/j.1532-5415.2007.01308.x

PMid: 17767685

8. Maes M, Galecki P, Chang YS, Berk M. A review on the oxidative and nitrosative stress (O\&NS) pathways in major depression and their possible contribution to the (neuro) degenerative processes in that illness. Prog Neuropsychopharmacol Biol Psychiatry 2011;35(3):676-92. https://doi.org/10.1016/j. pnpbp.2010.05.004

PMid:20471444

9. Gupte AA, Lyon CJ, Hsueh WA. Nuclear factor (erythroidderived 2)-like-2 factor (Nrf2), a key regulator of the antioxidant response to protect against atherosclerosis and nonalcoholic steatohepatitis. Curr Diab Rep 2013;13(3):362-71. https://doi. org/10.1007/s11892-013-0372-1

10. Xu H, Barnes GT, Yang Q, Tan G, Yang D, Chou CJ, et al. Chronic inflammation in fat plays a crucial role in the development of obesity-related insulin resistance. J Clin Investig 2003;112(12):1821-30. https://doi.org/10.1172/jci200319451 PMid: 14679177

11. Kobayashi EH, Suzuki T, Funayama R, Nagashima T, Hayashi M, Sekine $\mathrm{H}$, et al. Nrf2 suppresses macrophage inflammatory response by blocking proinflammatory cytokine transcription. Nat Commun 2016;7(1):1-4. https://doi.org/10.1038/ncomms11624 PMid:27211851

12. Ahmed SM, Luo L, Namani A, Wang XJ, Tang X. Nrf2 signaling pathway: Pivotal roles in inflammation. Biochim Biophys Acta Mol Basis Dis 2017;1863(2):585-97. https://doi.org/10.1016/j. bbadis.2016.11.005

\section{PMid:27825853}

13. Kim JE, You DJ, Lee C, Ahn C, Seong JY, Hwang JI. Suppression of NF-KB signaling by KEAP1 regulation of IKK $\beta$ activity through autophagic degradation and inhibition of phosphorylation. Cell Signal 2010;22(11):1645-54. https://doi.org/10.1016/j. cellsig.2010.06.004

\section{PMid:20600852}

14. Harrison C. BTK inhibitor shows positive results in B cel malignancies. Nat Rev Drug Discov 2012;11(2):96. https://doi. org/10.1038/nrd3656

PMid:22262035

15. Joshi G, A Johnson J. The Nrf2-ARE pathway: A valuable therapeutic target for the treatment of neurodegenerative diseases. Recent Pat CNS Drug Discov 2012;7(3):218-29. https://doi.org/10.2174/157488912803252023

PMid:22742419

16. Martín-de-Saavedra MD, Budni J, Cunha MP, GómezRangel V, Lorrio S, Del Barrio L, et al. Nrf2 participates in depressive disorders through an anti-inflammatory mechanism. Psychoneuroendocrinology 2013;38(10):2010-22. https://doi. org/10.1016/j.psyneuen.2013.03.020

PMid:23623252

17. Mendez-David I, Tritschler L, El Ali Z, Damiens MH, Pallardy M, David DJ, et al. Nrf2-signaling and BDNF: A new target for the antidepressant-like activity of chronic fluoxetine treatment in a mouse model of anxiety/depression. Neurosci Lett 2015;597:121-6. https://doi.org/10.1016/j.neulet.2015.04.036 PMid:25916883

18. Martín-Hernández D, Caso JR, Meana JJ, Callado LF, Madrigal JL, García-Bueno B, et al. Intracellular inflammatory and antioxidant pathways in postmortem frontal cortex of subjects with major depression: Effect of antidepressants. J Neuroinflammation 2018;15(1):251. https://doi.org/10.1186/ s12974-018-1294-2 PMid:30180869

19. Perry JJ, Shin DS, Getzoff ED, Tainer JA. The structura biochemistry of the superoxide dismutases. Biochim Biophys Acta 2010;1804(2):245-62. https://doi.org/10.1016/j. bbapap.2009.11.004

PMid:19914407

20. Hamilton M. Standardised assessment and recording of depressive symptoms. Psychiatr Neurol Neurochir 1969;72(2):201-5.

PMid:5792061

21. Fateem L. Arabic Manual of Hamilton Depression Scale. Cairo, Egypt: The Anglo-Egyptian Bookshop; 1994.

22. Misra HP, Fridovich I. The role of superoxide anion in the autoxidation of epinephrine and a simple assay for superoxide dismutase. J Biol Chem 1972;247(10):3170-5.

PMid:4623845

23. Ohkawa H, Ohishi N, Yagi K. Assay for lipid peroxides in animal tissues by thiobarbituric acid reaction. Anal Biochem 1979;95(2):351-8. https://doi. org/10.1016/0003-2697(79)90738-3

PMid:36810

24. Whittemore ER, Loo DT, Watt JA, Cotmans CW. A detailed analysis of hydrogen peroxide-induced cell death in primary neuronal culture. Neuroscience 1995;67(4):921-32. https://doi. org/10.1016/0306-4522(95)00108-u

PMid:7675214

25. Maes M. Major depression and activation of the inflammatory response system. In: Cytokines, Stress, and Depression. Boston, MA: Springer; 1999. p. 25-46.

26. Efe H, Değer O, Kirci D, Karahan SC, Örem A, Calapoğlu M. 
Decreased neutrophil antioxidative enzyme activities and increased lipid peroxidation in hyperlipoproteinemic human subjects. Clin Chim Acta 1999;279(1-2):155-65. https://doi. org/10.1016/s0009-8981(98)00178-8

27. Bilici M, Efe H, Köroğlu MA, Uydu HA, Bekaroğlu M, Değer O. Antioxidative enzyme activities and lipid peroxidation in major depression: Alterations by antidepressant treatments. J Affect Disord 2001;64(1):43-51. https://doi.org/10.1016/ s0165-0327(00)00199-3

PMid:11292519

28. Bajpai A, Verma AK, Srivastava M, Srivastava R. Oxidative stress and major depression. J Clin Diagn Res 2014;8(12):CC04-7. PMid:25653939

29. Camkurt MA, Fındıklı E, İzci F, Kurutaş EB, Tuman TC Evaluation of malondialdehyde, superoxide dismutase and catalase activity and their diagnostic value in drug naïve, first episode, non-smoker major depression patients and healthy controls. Psychiatr Res 2016;238:81-85. https://doi. org/10.1016/j.psychres.2016.01.075

30. Mazereeuw G, Herrmann N, Andreazza AC, Khan MM, Lanctôt KL. A meta-analysis of lipid peroxidation markers in major depression. Neuropsychiatr Dis Treat 2015;11:2479. https://doi.org/10.2147/ndt.s89922

PMid:26491326

31. Zhang JC, Wu J, Fujita Y, Yao W, Ren Q, Yang C, et al. Antidepressant effects of TrkB ligands on depression-like behavior and dendritic changes in mice after inflammation. Int J Neuropsychopharmacol 2015;18(4):pyu077. https://doi. org/10.1093/ijnp/pyu077 PMid:25628381

32. Rangaswamy R, Swathi K. Study of biochemical markers of oxidative and nitrosative stress pathways in major depression.
J Evol Med Dent Sci 2014;42(3):10448-53. https://doi. org/10.14260/jemds/2014/3360

33. Kotan VO, Sarandol E, Kirhan E, Ozkaya G, Kirli S. Effects of long-term antidepressant treatment on oxidative status in major depressive disorder: A 24-week follow-up study. Prog Neuropsychopharmacol Biol Psychiatry 2011;35(5):1284-90. https://doi.org/10.1016/j.pnpbp.2011.03.021 PMid:21515329

34. Bal N, Acar ST, Yazici A, Yazici K, Tamer L. Altered levels of malondialdehyde and vitamin $\mathrm{E}$ in major depressive disorder and generalized anxiety disorder. Dusunen Adam 2012;25(3):206. https://doi.org/10.5350/dajpn2012250302

35. Rawdin BJ, Mellon SH, Dhabhar FS, Epel ES, Puterman E, Su Y, et al. Dysregulated relationship of inflammation and oxidative stress in major depression. Brain Behav Immun 2013;31:14352. https://doi.org/10.1016/j.bbi.2012.11.011 PMid:23201587

36. Sarandol A, Sarandol E, Eker SS, Erdinc S, Vatansever E, Kirli S. Major depressive disorder is accompanied with oxidative stress: Short-term antidepressant treatment does not alter oxidative antioxidative systems. Hum Psychopharmacol 2007;22(2):6773. https://doi.org/10.1002/hup.829 PMid: 17299810

37. Stefanescu C, Ciobica A. The relevance of oxidative stress status in first episode and recurrent depression. J Affect Disord. 2012;143(1-3):34-8. https://doi.org/10.1016/j.jad.2012.05.022 PMid:22840610

38. Maes M, Vandoolaeghe E, Van Hunsel F, Bril T, Demedts $P$, Wauters $\mathrm{A}$, et al. Immune disturbances in treatment-resistant depression: Modulation by antidepressive treatments. Hum Psychopharmacol 1997;12(2):153-62. https://doi.org/10.1002/ (sici)1099-1077(199703/04)12:2<153::aid-hup852>3.0.co;2-n 